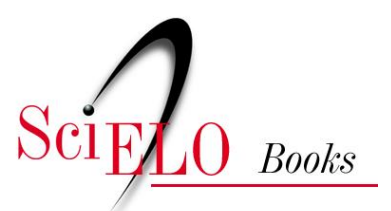

\title{
El rostro y la otredad de Emmanuel Levinas como elementos de alteridad y su implicación en el personalismo cristiano
}

\author{
Víctor Adolfo Iza Villacís
}

\section{SciELO Books / SciELO Livros / SciELO Libros}

IZA VILLACÍS, V.A. El rostro y la otredad de Emmanuel Levinas como elementos de alteridad y su implicación en el personalismo cristiano. In: IZA VILLACÍS, V.A., ed. Persona, educación y filosofia: reflexiones desde la educación universitaria [online]. Quito: Editorial Abya-Yala, 2018, pp. 67-84. ISBN: 978-9978-10-493-4. https://doi.org/10.7476/9789978104934.0005.

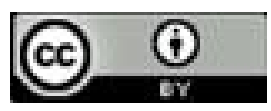

All the contents of this work, except where otherwise noted, is licensed under a Creative Commons Attribution 4.0 $\underline{\text { International license. }}$

Todo o conteúdo deste trabalho, exceto quando houver ressalva, é publicado sob a licença Creative Commons Atribição 4.0.

Todo el contenido de esta obra, excepto donde se indique lo contrario, está bajo licencia de la licencia $\underline{\text { Creative }}$ Commons Reconocimento 4.0. 


\section{El rostro y la otredad de Emmanuel Levinas como elementos de alteridad y su implicación en el personalismo cristiano}

Víctor Adolfo Iza Villacís ${ }^{1}$

\section{Resumen}

Ingresar en el estudio de la alteridad como respuesta ética en un afán de desestructurar al antropocentrismo es realmente una aventura, y una muy apasionante. La propuesta filosófica del siguiente estudio reflexivo para el personalismo desde Levinas devela el rasgo de la alteridad como respuesta en el otro, bajo su mirada, su rostro, su presencia sin estructura individual que rompe con la indiferencia. Es para él una estructura ética que nos arrebata respuesta. En este sentido el personalismo se revitaliza con la reflexión permanente y posibilita en algunos casos una praxis donde la teoría puede hacerse vida. La alteridad no es un concepto etéreo, puede concebirse como alumbramiento desde el amor. La ética primera anunciada por Levinas no es un concepto alejado sino algo que puede ser posible

1 Master en Filosofía por la Universidad Pontificia Bolivariana de Medellín Colombia. Doctorando en Filosofía por la Universidad Pontificia Bolivariana de Medellín Colombia. Master en Pastoral Universitaria por la Universidad Salesiana del Ecuador. Catedrático de las materias humanísticas en la UPS sede Guayaquil.viza@ups.edu.ec 
como ha sido posible pensar a la filosofía no como el amor a la sabiduría sino como la sabiduría del amor, lo que genera un cambio de paradigma. "En mi filosofía no es la libertad la primera noción. Es la "heteronomía" y no el "saber". Es la responsabilidad implicando en ello la sujeción a otro" (Sudar, 1979).

Palabras clave: Alteridad, Levinas, persona, responsabilidad, rostro.

\section{Abstract}

Entering into the study of alterity as an ethical response in an endeavor to destroy anthropocentrism is really an adventure, and a very exciting one. The philosophical proposal of the following reflective study for personalism since Levinas reveals the feature of alterity as an answer in the other, under his gaze, his face, his presence without individual structure that breaks with indifference. It is for him an ethical structure that takes away our response. In this sense personalism is revitalized with permanent reflection and in some cases makes possible a praxis where theory can become alive. Otherness is not an ethereal concept, it can be conceived as lighting from love. The first ethics announced by Levinas is not a distant concept but something that may be possible as it has been possible to think of philosophy not as the love of wisdom but as the wisdom of love, which generates a paradigm shift. "In my philosophy, freedom is not the first notion. It is "heteronomy" and not "knowledge". It is the responsibility to involve subjection to another".

Keywords: Alterity, person, face, responsibility, Levinas.

\section{Introducción}

Vasto es el universo, pequeño el mundo que habitamos, como "hormigas" construimos realidades, nos paseamos frente a otros con el poder de nuestras creaciones. Infinitas son las posibilidades de que las cosas fueran distintas a como son y sin embargo son así como están y como se las conoce. Nos develan verdades que no son absolutas pues cada una de ellas ayuda a otras a develarse. Y sin embargo este 
ser "humano" del humus tierra, sigue siendo un total desconocido, capaz de las mejores obras de arte y de música, bellas melodías y de los grandes siniestros humanos. De pavor y terror, de guerra y hambre, de armamento y suicidios. Tiende su mano hacia el infinito y se carga la energía del sol y de las estrellas, sigue alzando una mirada al cielo para perpetuar su especie con el afán de esperanza.

Lo alcanzado en avances tecnológicos, científicos y médicos es un constante desafío a su propia capacidad de investigación, búsqueda de confort y sanación. Los conocimientos que se han alcanzado a través del descubrimiento del vasto universo, siguiendo las líneas del pensamiento de Einstein, con los presupuestos de la física y la mecánica cuántica proponen posibilidades inmensas para la comprensión de un mundo y una totalidad que se expande con la imaginación.

El conocimiento es el lenguaje del mundo académico. El sentir como siempre está ligado a un mundo de sospecha y de subjetividades que no alcanzan a relacionarse del todo en un mundo normalizado y reglamentado en una homogeneidad que reclama igualdad pero que vomita de su boca a lo distinto (Chul-Han, 2017). La racionalidad o racionalismo se ha engrandecido en el pensar antes de existir, negando lo que por naturaleza somos. El sentir también ha querido presentarse como una nueva manera de vivir y expresarse. Soy lo que siento es la premisa. Si siento que soy un perro entonces reclamo el derecho a ser tratado como perro, porque importa más el sentir que lo que de verdad soy, la verdad entonces se vuelve una situación o creada o sentida por el individuo o sujeto que la re-crea. La conciencia universal de humanidad, idea, la cual muchos estudiosos de la filosofía ética han impulsado, generando un proceso utópico desligado de lo social, más bien empotrado en el sentido nos ha dado vinculaciones a una facultad más holística y sin embargo esta percepción del mundo desde estas propuestas no pueden romper esquemas de límites, pasaportes, ciudadanía e identidades (Santos, 2004).

Por un lado entonces el conocimiento con elementos que aparecen en la palestra de las revistas académicas, por donde ronda hoy 
por hoy la reflexión científica, la economía, la ciencia médica, la política, incluso el armamentismo. El conocimiento ligado a la investigación como búsqueda de un planeta habitable y cercano, o la posibilidad de que esos planetas ya descubiertos puedan alojar a nuestra especie. Lo hemos agotado y nos hemos autoexplotado bajo el fuego certero del poder seductor (Chul-Han, 2014), ¡cuánto hay para producir reflexión a través de la cual se despersonaliza al ser humano!

Por otro lado la era de la trascendencia humana ligada a la idea de "Dios" ha quedado muy lejana y a veces se la percibe cercana porque el humano sigue esperando esperanza. ${ }^{2}$ La ética se percibe como una arrendataria de la moral. Se ha mudado a otros ambientes donde duerme oculta frente a las infinitas posibilidades de la ciencia, donde la dejan dormir tranquila para no alterar, ni frenar ninguno de los eventos programados para ser analizados a futuro. La robótica ligada al estudio de células madres, creando un homo evolutis (Henriquez y Gullans, 2010) que orbita al ser humano como un cometa esperando el acercamiento oportuno para arrebatarle su centralidad y sus desenfrenos.

Socialmente la circunstancia actual de la humanidad no es un panorama alentador para la reestructura ética. No conformes con la muerte de "dios", se "mata" al hombre y a la mujer, se le impone formas de mirarse a sí mismo y al otro, de valorarse y estructurarse sin sentido del absoluto o de la trascendencia, a veces innaturales o contraindicadas para construir humanidad.

Emanuel Levinas, en el siglo pasado, pero aún muy cercano presenta una filosofía original que ha ido calando en la estructura social

2 En el libro La edad dela nada, se presenta un estudio bastante prolongado de aquello que sucedió en el mundo luego de que Nietzche presente su idea de la muerte de Dios. La idea del Trascendente ligado a la religión va estructurando el secularismo que en cierta manera le "arrebata" el "monopolio" y se presentan innumerables maneras de comprender la idea de la trascendencia desde el ser humano. Ya sea la psiquis como la situación existencial, la búsqueda del sentido o el trabajo por la justicia o la idea de una humanidad más ética lo que da carácter de trascendencia al obrar humano (Watson, 2014). 
y comunitaria, sus ideas clarifican un aspecto ético de la relación y un intento de develación del ser desde el otro. La idea de que el otro y el rostro cuestionan al ser y a la vez lo proyectan y lo retienen, aún hoy resulta extraño. Tomando en consideración a García, estudioso de la filosofía de la alteridad, leemos "no es extraño, que sus obsesiones lo lleven a desconfiar de todo atisbo de totalidad y, para ello, jamás pierde de vista la infinitud del Otro... Rostro que ríe y saluda, rostro que sufre y me exige respuesta, rostro que me seduce y cautiva" (García, 2010).

La filosofía de la otredad y la ética como filosofía primera da razones para la importancia de la alteridad y su importancia ligada a la ética de la persona. Filosofía y ética que conmociona al interior de la persona en especial por la interpelación frente a la otredad, al rostro, la mirada que no deja de lado al sí mismo, sino que impulsa a una reflexión sobre la manera como nos interpretamos y por lo tanto nos comprendemos. La filosofía de Lévinas, se caracteriza por el acceso al otro en estado ético, incluso "minimizando" al onto (ser) para que su "superioridad" comprenda que se sujeta en y desde el otro, con su mirada, voz, tragedia y gozo. Y es el otro, según Levinas quien "engendra" al ser (sí mismo) desde el infinito y es en el otro "sin rostro" concreto donde puede descubrir la verdad de su mismidad. Y descubre una verdad que le ha sido oculta, la verdad sobre la misma existencia, la verdad sobre la responsividad en el mundo y por el otro, he aquí el aparecimiento de la ética como respuesta. En el rostro del otro habita la certeza incluso de mi pasividad, la otredad se vuelve mismidad, "es decir" alteridad. La mirada en el rostro del otro es certera y certeza. Me convida pero al mismo tiempo me retiene. No solo me cuestiona también es la que me permite ser consciente de mi propio gozo, de mi propio sentido.

Levinas, desde la filosofía y la ética, en su reflexión fenomenológica del ser en el otro, nos impulsa a pensar en categorías de relación, diálogo y encuentro, posibilitando una reflexión más amplia del personalismo en las interrelaciones humanas. El rostro es infinito, no pertenece a alguien concreto, es una estructura que permite al sí 
mismo descubrirse totalmente desde la alteridad. Cuando Emanuel Levinas levanta la mirada de la fenomenología y el existencialismo, nos lleva de manera oportuna al humanismo a través de la ética. Los códigos comportamentales no tienen valor alguno si no están relacionados con un estado de apertura a la otredad, quedan anulados o sin sentido o pertenecen a un absurdo nihilismo pues no observa al otro como alteridad sino como objeto utilitario para el yo. Toda relación humana se establece por un ser que rompe con la mismidad con el yo encerrado e indiferente. Esta alteridad es ser el otro, en el otro, por el otro. No somos capaces de ser por nosotros mismos sin el otro. Es el otro quien ha decidido en un momento dado de nuestra existencia por nosotros, decide al ver nuestro rostro y da respuesta, se "responsiviza" en un acto de presencia, tal vez de amor, tal vez de responsabilidad. Siendo unos niños, son nuestros padres quienes deciden y responden ante nuestro rostro, es nuestra otredad la que les llama a dar respuesta y nos cuidan, nos protegen. Acto de alteridad humana que está en la historia y en el infinito (Levinas, 2012).

Sin embargo la pregunta vuelve a estar en la palestra de la reflexión filosófica en especial sobre la ética. ¿Dónde inicia la ética levinasiana? ¿En la mismidad? ¿En la otredad? La ética es filosofía primera por ser fundamento de la otredad y por enajenarme de mi mismidad para ser rehén del otro. Sin embargo soy responsable sin el acto, sin tiempo ni espacio. Estoy consagrado al otro incluso antes de ejercer mi libertad, mi tiempo, mi ser (Levinas, 2006).

¿Cómo ejercer esta ética en el momento actual desde la mirada y el rostro? Byung Chul-Han en su libro La expulsión de lo distinto enmarca las situaciones actuales en las que la alteridad se desmorona o ha tomado un significado diferente, atópico como lo designada el filósofo. La igualdad pesa más que la extrañeza y lo distinto es expulsado a causa del miedo. Impuesto, y desarticulado (Chul-Han, 2017). Así el mapa de la fenomenología nos lleva a incursionar en un desafío para comprender la respuesta desde la otredad y la alteridad como camino ético. ¿Cómo atañe esto en el personalismo actual, desde la humanidad del rostro sin la especificidad del acto y la intencionalidad? 


\section{La alteridad como análisis del ser}

Para Levinas el rostro del Otro nos hace su rehén, nos responsabiliza, pero ¿cómo llegamos a él en alteridad?. Por lo que debe quedar claro que, como lo dice Levinas en una entrevista cuando le preguntan sobre la fenomenología del rostro, a lo que muy claramente dice que no hay una "fenomenología" del rostro, pues no es un objeto concreto como tal sino que está, es.

...Pienso, más bien, que el acceso al rostro es de entrada ético. Cuando usted ve una nariz, unos ojos, una frente, un mentón, y puede usted describirlos, entonces usted se vuelve hacia el otro como hacia un objeto. ¡La mejor manera de encontrar al otro es la de ni siquiera darse cuenta del color de sus ojos! ${ }^{3}$

Así comprendiendo que la base de la alteridad es la ética nos ligamos a pensar como Levinas en su libro Dios, la muerte y el tiempo, donde sostiene que la ética incluso es antes de ser. Como si hubiera un círculo infinito en la relación. No como si fuera de ida o vuelta o una estructura lineal, sino circular que nace en el infinito y que no se agota jamás pues su misma fuerza gravitacional le permite la fuerza de la relación en diálogo. No es un diálogo de dos, no son un tú y un yo que se retraen al hablar o al presentarse físicamente, esto los supera en el tiempo y en el espacio, los excede en su propia existencia. Cuando entramos en el círculo en este acontecer incluso la muerte no es el final sino parte del proceso de relación, ni el nacer un inicio (Levinas, 2016). En este proceso de significaciones no hay lenguaje que posibilite un entendimiento mayor sino la ética. Ese acceso al rostro desnudo y pobre que me afecta y me altera, me provoca y me hace es profundamente ético.

El carácter trascendente del ser en Levinas es por la comprensión de la otredad como lo que me excede es decir luchar por escapar de nuestra condición, cosa que es profundamente laboriosa, dolorosa y

3 Entrevista de Philipe Nemo a Levinas. Ethicsand Infinity. Dialogues of Emmanud Leinas and PhilippeNem (1984). Disponible en https://goo.gl/xhbgKz 


\section{4}

ligada en ocasiones al fracaso. Este carácter trascendente del ser se frena por la "insuficiencia de la subjetividad" para trascenderse a sí misma, situación límite si recordamos que Heidegger nos habla de lo imposible de salir del mundo, o encontrarnos "fuera" de él, si vamos más lejos, el ser humano no podría trascender su propia subjetividad cosa que cuestiona la trascendencia. Este carácter de excedencia se muestra como una enérgica fuerza ética que arranca del ser la autonomía y le brinda al mismo ser una posibilidad. El "no matarás" que arrebata a la locura de no hacer de lo violento un lenguaje, trasciende la idea condicionada a la cual la especie humana se inclina. Es la alteridad y la ética una salida esperanzadora. Ser o no ser ya no es el dilema absoluto, sino responder o no frente al otro como excedencia de ser para alcanzar un carácter menos subjetivo y así involucrar a la trascendencia en este juego perpetuo de la existencia (Watson, 2014, pp. 457-459).

Hasta aquí tres elementos claves: alteridad, ética y trascendencia, con estrategias ligadas a la libertad de ser como son la responsividad y la estructura de la otredad como infinita. Este carácter de la libertad lo expresa Levinas en uno de sus libros ligados a su "estado" teológico, siendo este presupuesto una crítica a su filosofía, pues se liga a otra tradición que se desprende de la tradicional griega y ontológica para situarse desde la tradición talmúdica judía, cuestión que amerita una consideración de carácter teológico que sin embargo para nuestro estudio no le quita nada a su esencia filosófica "sino al contrario" le da fortaleza a su carácter emprendedor y original. En especial porque la perspectiva del encuentro con Dios y con el otro va ligado a la praxis (Levinas, 2008, pp. 395-416).

Más Levinas no se queda en un ambiente teológico más si cabe la expresión "saca” de esa tradición el valor del otro, del extraño, el extranjero, el sin rostro para devolverle la mirada y desde la filosofía aportarle una comprensión válida para la el infinito y la trascendencia, de la totalidad y la subjetividad. No hay mezcla continua o difusa, sino la plena comprensión que el ser no es solamente la totalidad sino que "abarca" cuando se excede a sí mismo al infinito, 
y este abarcamiento no es de apropiación, ni de donación, el autor de Totalidad e Infinito lo llama rehén del otro. Tal vez buscando un enlace para mi propia comprensión, la posibilidad frente la sumisión Islámica de la palabra musulmán permita entender este acallamiento del ser frente al Otro, el grande, el innombrable, o en la tradición cristiana la obediencia plena a la voluntad del Padre como totalmente otro en el cual me fundo en libertad sumisa y austera.

\section{La responsabilidad como respuesta}

Responder como un acto ético es salir de sí mismo o vivir para sí en un acto de responsabilidad irrecusable e intransferible como muy bien lo anota el siguiente párrafo de Levinas:

Esta inversión humana del en-sí y del para-sí, del -cada cual para sí mismo- en un yo ético, en la prioridad del para-otro, esta sustitución del para-sí de la obstinación ontológica por un yo que en tal caso es sin duda único, pero único por su elección de una responsabilidad respecto de otro hombre -irrecusable e intransferible-, esta inversión radical se produce en lo que llamamos encuentro con el rostro del otro. (Levinas, 1993, pp. 249-255).

Si se vive solo para sí es imposible el encuentro, la respuesta, la responsividad o responsabilidad desde y por el otro. Con respecto a la respuesta y su intencionalidad es necesario enfrentarla con la realidad de la conciencia, encontrando en Miguel García-Baró una presentación del problema:

La teoría acerca de la intencionalidad de la conciencia es el nudo central de todos los problemas de la filosofía. El fenómeno sobre el que versa esta teoría es el modo, extraordinariamente admirable, como la conciencia revela el valor, la existencia y el contenido de todo cuanto es (García-Baró, 1991, pp. 247-269).

El tema de la conciencia interior o exterior que da paso al divorcio entrañable entre Husserl y Sartre en su perspectiva ontológica que recurren al Ego y el yo, mientras tanto Levinas nos hace voltear la mirada para ser conscientes de quien encuentra en mi conciencia 
su propia conciencia es el otro, pero tiene viceversa, doble vía. La intencionalidad es ética y la realidad se percibe en la mirada, no la que mira el ser sino de la que es mirada. La mirada como vehículo de vergüenza, de crecimiento, de pasividad o de respuesta. "El "yo" se concibe como Yo y, sin embargo, sigue siendo único en la imposibilidad de sustraerse al otro hombre" (Levinas, 2016, p. 164). Es una vuelta que no sale del ser para representar sino que es el ser quien es cuestionado de algún modo en su propio proceder y existencia. La intencionalidad no es mía, no es una facultad absoluta del ser, en este caso la respuesta la he tenido en mí porque el otro ya ha respondido por mí sin tiempo, ni espacio, sino más allá, en la historia infinita.

Volteemos por un momento la página hacia Kant y la ética del deber, como un acto del sujeto que se reestructura en Levinas por la ética de la respuesta, en este caso el "deber" de responder no solo por sí mismo sino por el otro, se convierte en un acto que brota de la libertad personal descubierta en la presencialidad del otro, y este otro que nos impulsa a un deber requiere una respuesta por el que no tiene voz, por el que no puede responder, en este caso y muchas veces un embrión, un ser humano indefenso. No me atrevo a pensar que la otredad se manifiesta en un animal, o en la propia naturaleza, sin embargo me pregunto ¿Es posible ver el rostro más allá de la persona? ¿Puede ser la otredad un carácter ligado a lo natural? ¿No se confunde al ente con onto en este momento de la historia?

Como un ejemplo de esta confusión es el haber promovido e integrado en la Constitución del Ecuador a la cosmovisión indígena de los múltiples pueblos originarios del Ecuador, la Pacha $\mathrm{Mama}^{4}$ y el Suma Kawsay (Buen vivir), en el cual se comprende que la tierra palpita como otro y "tiene" derechos. Es el hombre ecuatoriano quien racionaliza su papel en la tierra y otorga derecho a quien nos

4 En su libro presenta un pensar a la naturaleza como objeto a sujeto, una situación que provoca nuevos desafíos (Bautista, 2014). 
ha dado el derecho a la vida como una respuesta profunda y entrañable para responder por ella.

De la Constitución del 2008:

Artículo 71.- La naturaleza o Pacha Mama, donde se reproduce y realiza la vida, tiene derecho a que se respete integralmente su existencia y el mantenimiento y regeneración de sus ciclos vitales, estructura, funciones y procesos evolutivos (Constitución de la República del Ecuador, 2008).

Sin embargo es posible pasar de un antropocentrismo profundamente egoísta a una relación más "compasiva” con aquello que nos excede, que no somos pero que nos hace, y en este caso el espíritu de la naturaleza en las cosmovisiones andinas, es otra vereda por donde nuestro pensar puede transitar, por lo tanto la confusión pretendida, muy bien puede fortalecer los grades de humanidad y ética si se comprenden como parte de una cosmovisión andina, a esto hace referencia Juan José Bautista en su estudio.

La respuesta frente a "los" desconocidos, es otra ingrata pero necesaria condición para despertar del olvido al que se ha sometido al otro y a sus rostros. Carretero en su artículo "El indigente trashumante" (León, 2009), y la interpelación de Chul-Han en La expulsión de lo distinto (2017, pp. 61-64) nos increpan en el absoluto dilema por el que ha sido puesto siempre en una posición de límite, sin poder ingresar al marco al cual le ha sometido la ontología del ser. El otro como relegado, el sometido, el espécimen raro de la evolución, el esclavizado, el indigente, el desconocido, el sin nombre, el innombrable. Y sin embargo este "sin rostro" nos ha hecho y ha respondido incluso sin antes haber conocido nuestro rostro ni habernos amado o descubierto en la mirada. El bien en el otro es la re estructura que debe recomponer la filosofía y el personalismo.

No hay respuesta desde el yo sino desde el otro hacia nosotros, siendo conscientes de esta inagotable fuente de exposición humana, es que podemos dar una respuesta ética con profunda alteridad. El 
amor brota como agradecimiento al comprender la estructura del rostro del otro en mí. El suspiro no se arranca de mí, sino que es dado hacia mí en el otro que me retiene, sin el cual no puedo ser, en el cual estoy sometido. En mi mismidad se da la expulsión de aquello que es distinto, Ese otro que no quiero en mí y que es mi propia otredad, al que le someto y no quiero retenerlo, al que me contrapongo al desencarnarme de la otredad en mí.

La respuesta como soledad en mí, es un aparta-se indiferente de la comunidad que me habita. Un caminar desértico en la propia inseguridad y lejanía, en la tristeza y desamparo. ¿Es acaso esa sensación de vacío del otro en mí la que me impulsa a querer someterlo, usarlo, cosificarlo, despersonalizarlo, hacer un bien para mi bienestar inválido de respuesta?

\section{Alteridad como respuesta y ética de la compasión}

$\mathrm{Al}$ inicio de este artículo hemos invadido al lector con premisas Levinasianas, tal vez un tanto desconcertantes. Hacia donde me lleva este río inagotable de la otredad si no es al otro, sin embargo como ya lo hemos notado y percibido no hay un yo sin la conciencia plena de la comprensión del otro en mí.

La alteridad como respuesta es responsabilidad. Sin embargo, cuál es la pregunta? ¿Hacerse responsable de qué? ¿Responder por el otro en qué sentido? ¿No es capaz el otro de responder por sí mismo? ¿Quién soy yo para creerme capaz de responder por el otro? Su amo, su sirviente, su interlocutor. No tiene voz el otro y derechos para defenderse...

Para dar respuesta hay que desprender el catalogar al otro desde su rostro simbólico o condicionado, dentro de la sociedad donde cumple un rol o se lo estandariza. Ese rostro concreto como "forma social (Sabido, 2009, p. 34) no me ayuda en el plano filosófico. Es el rostro no como ser en concreto sino como infinitud donde nuestro propio ser se devela. Es como totalidad este evento en el cuál todo se puede dar y que sin embargo es arrastrado a la infinitud del otro. Si pudiera expre- 
sarse esta respuesta no ejecutaría libertad, ni decisión pues estamos en ella desde la sumisión mismo de la corporalidad y la materia al tiempo y al espacio. La misma libertad trasciende a una respuesta porque si respondiera se condicionaría y ya no sería libertad. Responsividad es el otro en mí que no necesita de voz, ni de ideas, ni de preguntas para responderse. La responsividad no es responsabilidad como acto o como intención es como el "Dasein" de Heidegger, un estado perpetuo frente a la existencia humana por la cual transitamos. El acto ético si se pudiera darle un estado de acto, sin querer estacionarlo en una breve respuesta o decisión que se estaciona en un tiempo limitado y en un espacio concreto, no existe. No hay acto ético o respuesta ética para Levinas. La ética es en sí misma la filosofía y es primera porque nos adentra a la sabiduría del amor. El acto ético primordial es esta fuente inagotable de existencia conocida como amor y que en presencia de la otredad donde permanece el lenguaje se delata a sí mismo como compasión. El ser se apasiona en conjunto o en comunión con la otredad que le habita y de la cual es rehén. Su respuesta es un acto vital donde la esencia de la significatividad es el sentido pleno de la existencia no solo individual sino humana, y posiblemente no solo humana sino como participando de la existencia plena del universo. Ese rostro se concretiza en esa totalidad infinita donde habitamos sin presente, ni pasado, ni futuro, sino donde simplemente somos juntos.

El tiempo como limitación del ser o el espacio como acto dejan de ser un evento aislado para convertirse en un aspecto envolvente del ser y de la otredad en mí, pues como lo menciona Levinas y considera que el tiempo no existe por ejemplo cuando hay perdón o cuando la misericordia hace su aparecimiento. El perdón destroza el tiempo y el espacio, lo destruye y lo desmorona, lo revitaliza y lo renueva, le deja sin espacio y sin tiempo, le hace mortal y lo detiene y la misericordia no compone ni destruye emerge a una nueva estructura de ser. Ya no hay desconocido ni rasgos sociales que puedan limitarlo. A La misericordia no le es necesario ninguna estructura de clase para parecer. Destruye todo catálogo y toda apariencia. Es el fuego que quema la boca del profeta Jeremías porque arrebata el miedo, la edad y la inseguridad. 
80

\section{Entre la otredad y el antropocentrismo, la persona}

Básicamente la fenomenología del otro y la base ética fundacional de la ética Levinasiana nos expulsa del pensar a sí mismo como antropocentrismo ontológico, por este motivo dentro de los nuevos estudios se toma en cuenta los fundamentos antropológicos para y hacia la persona y la humanidad, así mismo se presenta en la actualidad una bioética del personalismo buscando siempre la defensa de la dignidad de la persona. Por otro lado es necesario dejar de fragmentar el estudio de la persona humana y tampoco una desestructura sintética, sino una síntesis holística que comprende a la persona desde toda su estructura, por supuesto tomando en cuenta que el hombre sigue siendo un misterio y una complejidad (Burgos, 2016).

No hay una contraposición entre la otredad y la persona. El quien es identificativo como totalidad y el otro es quien en sí mismo. Cuando se habla de la persona no solo se piensa desde un quien sino desde otro-quien que me habita en mi subjetividad. El mundo interior del sujeto se complementa con la otredad que ha sido y se va construyendo con la realidad del otro. Ser persona no es un sí mismo, acceden a mí también a través del otro, sin embargo la subjetividad si bien es cierto es aportada desde el otro, es ese espacio donde idénticamente soy yo y respondo. Y también puedo no responder por mi libertad que es absoluta. Entonces es parte de esa decisión también la indiferencia y la falta de humanidad. No es un acto externo la maldad nace también en la no respuesta del otro y hacia el otro desde mi libertad. El mundo interior ese lugar casi "sagrado" sacro permanente y desnudo para sí mismo me arranca hacía el sentido de la vida y de la existencia. Ese lugar donde el rostro del Alguien se hace experiencia y no es algo solo intuitivo o elucubración. Entonces la experiencia de sentido como nos invita a la vida Grondin en las últimas líneas de su libro sobre el sentido de la vida, cuando habla de la trascendencia de sí, nos invita a vivir como esperanza, una esperanza que es capaz de aceptar la justicia sin bien, solo por el bien que le habita. $\mathrm{Y}$ a hacer lo que es bondadoso solo por el hecho de ser el bien en sí mimo. Es decir una esperanza que 
totaliza mi respuesta. Este bien que nace del sentido de la vida y de la misma esencia del ser humano y esté bien que "me habita" está en la misma esencia del otro, ese bien también me ha sido dado porque hay bien en el otro (Grondin, 2011, pp. 151-157).

En esta posición de ser persona como libertad y hacer de mí mismo lo que elijo ser y poder disponer de mí mismo puede contribuir a un estado de anarquismo contemporáneo y psicológico de la sociedad actual o lo que percibimos. Es así que el personalismo puede caer también en una posibilidad de autodeterminación que contribuye a la indiferencia, al egoísmo y a la falta de compasión que no reacciona frente al sufrimiento e incluso frente a la esperanza y el bien que me brinda el otro. Parece que la elección de la libertad de lo que quiero ser y de la ética como sabiduría del amor nos permite no una elección sobre lo que pretendo ser sino sobre lo que soy, el bien en mí y el bien del otro en mí por mi situación de rehén. No es entonces solo una libertad ligada al querer ser alguien sino sobre el ser que soy en el bien de mi totalidad ligada al infinito en una ética que posibilita una trascendencia del propio ser como humanidad y no solo como ser individual. Lo holístico no es comprender solo la naturaleza humana sino la esencia absoluta de la humanidad la cual me es dada como gracia, don o regalo y con la cual respondo como tarea y construcción en comunidad y compromiso.

\section{A manera de conclusión}

Parados frente al mundo, llevando en sí no solo al otro sino a la historia y el futuro humano.

Ahí de pie frente a lo que creemos que es la realidad y lo que observamos como interacción humana. Y a pesar de ser no queremos ser sino ser otros. Distinto a mí. Es una manera de otredad y de alteridad "marketizada" vendida como espectro de nosotros mismos, pero que no es real. Con esta "seudo tragedia" a lo Schopenhauer no podemos ver claro el rastro de la humanidad. Estamos invitados a destaparnos el rostro para ver la mirada de manera precisa y limpia. Habrá que lavar 
los ojos para ver el rastro del rostro que nos han dejado ver y que nos permiten comprender, si logramos alcanzar el inicio del camino.

Requiere valentía, capacidad de diálogo y encuentro, capacidad de solidaridad y compasión, capacidad de perdón, empatía y misericordia. Capacidad de internalizarse en la propia subjetividad para descubrir el bien que nos habita. Capacidad de aceptar la otredad no en el otro sino en mí. Capacidad para aceptar la sabiduría del amor como ética que nos invita a desprendernos del tiempo y de la trascendencia como espacio, o como visión a futuro esperanzada en un futuro incierto, sino bajo la comprensión profunda de que permanecemos en la trascendencia de nuestro propio ser.

Que es posible una revitalización de la persona desde la otredad y la responsividad no lo sé... No creo ya que haya que revitalizarse cuando se vive. Vivir es lo absolutamente necesario. Abrir los ojos al nacer ya es una respuesta, respirar es hacerse cargo del mundo. El oxígeno pasa por mí y hasta vive un cambio. Todo en mí es respuesta. $\mathrm{Al}$ vivir respondo al amor, al morir respondo al amor. Respondo a la vida. No solo se responde a la otredad sino desde la otredad porque nos habita. Y se responde a Dios: "Ir más allá de lo humano hacia lo divino. Captar lo Eterno en lo humano” (Levinas, 2013). Responder también es callar y el silencio es una respuesta, como llorar o cantar, en la praxis. Así como responder también es el dolor. Tenemos derecho al dolor en un mundo donde nos obliga a sonreír y "estar bien" como perpetuidad. Tenemos derecho a nuestra otredad.

No queda duda que la Otredad nos aporta un sentido de la vida desde otra vereda, desde una óptica y una tradición, que no es solo la griega, sin embargo en Latinoamérica queda pendiente, desde el plano investigativo el estudio de estas categorías como la alteridad, la mirada, el rostro, la otredad, la totalidad, el infinito en nuestra tradición pre colombina. Ligada a las culturas milenarias de nuestros pueblos. La comprensión de la persona en la actualidad latinoamericana tiene una comprensión sinérgica Europeo céntrica, griega, ju- 
deo-cristiana y de religiosidad multicultural de pueblos ancestrales que aún siguen vigentes en las tradiciones culturales.

No se puede dejar de lado, además, el hecho de que los avances tecnológicos como se los mencionó al inicio de este análisis y reflexión desde la alteridad y la otredad nos abren una interrogante sobre el otro como tecnología o como evolutis ¿Podría ser un robot en un futuro considerado persona, con derechos y capacidad de diálogo? Posiblemente la respuesta primera es no. ¿Podría amar un robot? ¿Podría personalizarse un artefacto electrónico? San Juan de la Cruz decía que "el amor no está en el ser que ama sino en el ser amado" (de la Cruz, siglo XVI) Si algún momento en un futuro los horizontes de la conciencia son superados ¿podría ser considerado un onto la máquina humana creada por los humanos? ¿Habrá la posibilidad de totalidad y de infinito fuera de la conciencia humana y de la persona-homo-hombre?

\section{Bibliografía}

Bautista, J. (2014). ¿Qué significa pensar desde América Latina? Madrid: Akal. Burgos, J.M. (2016). Las miradas del personalismo en el siglo XXI. Conferencia dictada en el Instituto Emmanuel Mounier, Buenos Aires, Argentina. 15 de septiembre. Disponible en: https://goo.gl/6BxT4m

Chul-Han, B. (2014). Neoliberalismo y nuevas técnicas de poder. Barcelona: Herder.

(2017). La expulsión de lo distinto (1 edición digital). Barcelona: Herder.

Constitución de la República del Ecuador (2008).

De la Cruz, J. (siglo XVI). Canto espiritual A.

Entrevista de Philipe Nemo a Levinas. Ethics and Infinity: Dialogues of Emmanuel Levinas and Philippe Nemo (1984). Disponible en: https:// goo.gl/qaMX3a

García, J. (2010). Sufrimiento, verdad y justicia. Alpha, 30, 169-180.

García-Baró, M. (1991). Introducción a un tratado de filosofía primera. Revista de filosofía $3^{a}$ época, IV(6), 247-269. Madrid: Complutense.

Grondin, J. (2011). Del sentido de la vida. Barcelona: Herder.

Henriquez, J. y Gullans, S. (2010). Homo Evolutis. México: New Word City. 
León, E. (Ed.). (2009). Los rostros del Otro. Reconocimiento, invención y borramiento de la alteridad. Anthropos Editorial. Universidad Autónoma de México.

Levinas, E. (1993). Entre nosotros. Ensayos para pensar en otro (en diálogos sobre pensar en otro). Pre-textos. (2006). Ética como filosofía primera. A parte Rei, 43,18. (2008). Dificil libertad. Buenos Aires: Lilmod.

(2012). Totalidad e infinito (segunda edición). Salamanca: Sígueme. (2013). Escritos Inéditos 1. Madrid: Trotta.

(2016). Dios, la muerte y el tiempo (sexta edición). Madrid: Cátedra.

Sabido, O. (2009). El extraño. Los rostros del Otro. Anthropos, Universidad Autónoma de México.

Santos, M. (2004). Por otra globalización: del pensamiento único a la conciencia universal. Bogotá: Andrés Bello.

Sudar, P. (1979). ¿El amor a la sabiduría o la sabiduría del amor? En diálogo con Emmanuel Levinas. Dialnet, 64.

Watson, P. (2014). La edad de la nada. El mundo después de la muerte de Dios. Barcelona: Crítica. 